\title{
PERCEPCIÓN DE «SÍ», PERCEPCIÓN DEL «OTRO»: LA CONSTRUCCIÓN DE IDENTIDADES POLÍTICAS URBANAS EN CASTILLA (EL CONCEJO DE CUENCA EN EL SIGLO XV) ${ }^{1}$
}

\author{
PERCEIVING THE «SELF», PERCEIVING THE «OTHER». \\ BUILDING POLITICAL IDENTITIES IN CASTILE \\ (THE CITY OF CUENCA IN THE FIFTHEENTH CENTURY)
}

\author{
JOSÉ ANTONIO JARA FUENTE \\ Universidad de Castilla-La Mancha
}

\begin{abstract}
Resumen: Durante el siglo XV, el mundo urbano castellano se vio enfrentado a la gravísima presión ejercida (no sólo sobre su alfoz) por la nobleza, las propias elites urbanas e incluso una débil monarquía (Juan II y Enrique IV) ansiosa de comprar las lealtades que necesita con el producto de la desmembración del realengo. En este contexto, uno de los mecanismos de defensa que opondrán las ciudades vendrá constituido por las categorías de identidad que, en este ámbito de construcción políticoconstitucional, cada entidad urbana fue capaz de imponer en su espacio de influencia. En el presente trabajo examinaremos cómo el concejo de Cuenca fue capaz de elaborar unas categorías identitarias, y de hacerlas reconocer por un amplio sector de la nobleza territorial a la que, de este modo, incorporó a la defensa del realengo (y, consiguientemente, del concejo y su tierra).
\end{abstract}

Palabras clave: Corona de Castilla. Siglo XV. Ciudades. Cuenca. Identidad política. Cláusulas de identidad.
Summary: In the fifteenth century, cities and towns in Castile were subjected to a strenuous pressure exerted (not only over their municipal jurisdictions) by the nobility, the urban elites and a weak monarchy (John II and Henry IV) anxious of buying loyalties with the product of the dismembering of the royal domain. In this context, one of the mechanisms of defence enforced by towns derived from the identity categories that, in this political-constitutional field, each urban entity was able to impose on its area of influence. In this study I will examine the case of the city of Cuenca, its ability to produce certain specific identity clauses, and its capacity to impose them to a relatively large number of members of the regional nobility, thus incorporating the later to the defence of the royal domain (and, consequently, to the defence of the city and its jurisdiction).

Keywords: Crown of Castile. Fifteenth century. Towns. Cuenca. Political identity. Identity clauses.

${ }^{1} \mathrm{El}$ presente estudio se inserta en el proyecto nacional de investigación Identidad política urbana. La construcción de modelos de identidad en las ciudades de Aragón. Castilla y Navarra (1350-1480), concedido por el Ministerio de Educación y Ciencia (HUM2006-01371), que dirijo desde la Universidad de Castilla-La Mancha.

Una primera versión. más reducida, de este trabajo se presentó como ponencia a la Seventh European Social Science History Conference, congreso internacional celebrado en Lisboa, los días 26 de Febrero a 1 de Marzo de 2008, con el título Perceiving the «self», perceiving the "others». an inquiry over the construction of political identities in fifteenth-century urban Castile. 


\section{SUMARIO}

Introducción.- 1. Identidad: un reservorio de valores compartidos.- 2. La construcción de marcadores de identidad.- 3. Contradicciones discursivas.- 4. Positivando las relaciones sociales.- Conclusiones.

\section{INTRODUCCIÓN}

La construcción de las elites urbanas en Castilla, durante la Edad Media, se desarrolló sobre la base, por un lado, de un proceso de selección operado desde el interior del grupo, merced al cual se venían a definir las señas de identidad que habrían de construir el principal requisito de inclusión/exclusión del grupo; y, por otro lado, a través de un proceso de competición que abarcaría, fundamentalmente, a miembros de la alta y mediana nobleza del reino (además de las propias elites urbanas, evidentemente). En ese último caso, la relación «universo noble»/elites urbanas no implicó, por parte de estas últimas, necesariamente la apropiación mimética de los valores de la nobleza. Esta relación no se construyó sobre unas bases relacionales unívocas sino dialécticas; implicó una interacción (permanente y más o menos intensa) a través de la cual las prácticas y valores propios del mundo noble fueron sometidas a un proceso de (relativa) redefinición, haciendo posible su manipulación política por parte de ambos colectivos.

El desarrollo de esas formas de identidad se presenta como un hito fundamental en el proceso de construcción política de dichos grupos sociales, y su estudio constituye una aproximación ideal para profundizar en el conocimiento, por un lado de los diversos procesos de construcción de colectividades y, por otro, de definición y ejercicio de las relaciones de poder $^{2}$. La alteridad que, desde un punto de vista urbano, se manifiesta en las

\footnotetext{
${ }^{2}$ Mediando influencias procedentes fundamental (aunque no exclusivamente) de la historiografía contemporánea, los estudios de identidad en el ambito medieval apenas sí han comenzado a despegar en algunos estudios y reuniones científicas, imposibilitando en este estadio toda aproximación de carácter comparatista, o al menos haciendo ésta en general francamente difícil. Por otro lado, en muchos de dichos trabajos se echa en falta un examen de la propia noción «identidad» que, en algunos trabajos, parece servir más como llamada de atención que como instrumento analítico. En cualquier caso y pese a las dificultades señaladas, se han publicado ya algunos estudios que merece la pena tener en cuenta. Desde un punto de vista más general, se trata, entre otros, de los trabajos de S. FORDE, Lesley JONSON y Alan V. MURRAY (eds.), Concepts of National Identity in the Middle Ages, University of Leeds, 1995; Donald MADDOX, Fictions of Identity in Medieval France, Cambridge University Press, 2000 (centrado en la producción literaria medieval, especialmente francesa); Henri BRESC y Christiane VEAUVY (dirs.), Mutations d'identités en Mediterranée. Moyen Age et époque contemporaine, Editions Bouchene, Condé-sur-Noireau, 2000; Jeffrey J. COHEN, Medieval Identity Machines, University of Minnesota Press, Minneapolis-London, 2003 (un trabajo mecanicista, con numerosas dificultades pero merecedor de alguna atención); Huw PRYCE y John WATTS (eds.), Power and identity in the Middle Ages: essays in memory of Rees Davies, Oxford, Oxford University Press, 2007. Con un carácter más específico pero incorporando algunas buenas teorizaciones, Jonathan FRIEDMAN, (ed.), Consumption and Identity, Harwood Academic Publishers, Chur (Suiza), 1994. Centrados en el ámbito de la historia urbana, cabe citar los estudios de Marc Boone y Peter, STABEL (eds.), Shaping urban identity in late Medieval Europe / L'apparition d'une identite urbaine dans l'Europe du Bas Moyen Age, Leuven, Garant, 2000; Giorgio CHITTOLINI Peter JOHANEK (coors.), Aspetti e componenti dell' identità urbana in Italia e in Germania (secoli XIVXVI) I Aspekte und Komponenten der städtischen Identität in Italien und Deutschland, Bolonia-
} 
relaciones surgidas entre lo propio (urbano) y lo extraño (noble) configura, pues, un marco idóneo de análisis para este tipo de estudios ${ }^{3}$.

En este sentido, el objeto central de este estudio será analizar los procesos de construcción y reconstrucción de dichas prácticas y valores en el marco de un altamente conflictivo siglo $\mathrm{XV}^{4}$. En este período, como es sabido, una fracción (cambiante) de la nobleza del reino se rebeló en diversas ocasiones contra la monarquía, forzando a las ciudades y villas (y a sus elites) a decidir en cada momento sobre su adhesión al partido monárquico o al rebelde. Será precisamente la relación nobleza/elites urbanas, en el contexto de estos conflictos, el punto neurálgico de un estudio que vamos a centrar en la ciudad de Cuenca en el siglo XV, utilizando así a esta ciudad como laboratorio de análisis ${ }^{5}$.

Efectivamente, dos argumentos fundamentales constituyen el hilo conductor del presente trabajo. De un lado, las interacciones (en numerosas ocasiones extraordinariamente conflictivas) que se producen entre la ciudad y la nobleza territorial (vecina y/o con intereses en la ciudad y su tierra); de otro, el modo en que los diversos actores sociales (nobleza y ciudad-elites urbanas) observaron, analizaron y construyeron y reconstruyeron, en suma percibieron no sólo dichas interrelaciones y sus interacciones sino también las propias condiciones sociopolíticas que contribuían a construir a unos y otros actores. En este sentido, el proceso de percepción ejecutado por los diversos agentes sociales no fue (no es) esencialmente pasivo sino activo, pues no sólo perseguía comprender a los diversos agentes y agencias envueltos en dichos procesos, así como el contexto en el que se desenvolvían, sino operar en él

Berlín, 2000; David, Gary SHAW, Necessary conjunctions: the social self in medieval England, New Cork, Palgrave Macmillan, 2005. Y, finalmente, para el ámbito hispano, aunque con un carácter más general, Itinerarios medievales e identidad hispánica, XXVII Semana de Estudios Medievales, Estella, del 17-21 de Julio de 2000, Gobierno de Navarra, Pamplona, 2001; y Carlos AYALA MARTÍNEZ, Pascal BURESI y Philippe JOSSERAND, Identidad y representacion de la frontera en la España medieval (siglos XI-XIV), Casa de Velázquez-Universidad Autónoma, 2001. Junto a los profesores Isabel ALFONSO ANTÓN y Georges MARTIN, soy coordinador de la obra Construir la identidad en la Edad Media. Poder y memoria en la Castilla de los siglos VII $a X V$, Universidad de Castilla-La Mancha, Cuenca (en prensa).

${ }^{3}$ Pierre TAP, Introduction, en Pierre TAP (dir.), Identités collectives et changements sociaux, Colloque International, Production et affirmation de l'identité, Toulouse, Septembre1979, Privat, Toulouse, 1980, pp. 11-15.

${ }^{4}$ En este sentido y aunque centrado en un análisis sobre el concepto de región, merece tenerse en cuenta el estudio que Pierre BOURDIEU dedica a L'identité et la représentation, "Actes de la recherche en sciences sociales», 35-1 (1980), pp. 63-72.

${ }^{5}$ Cuenca es una ciudad «afortunada» en materia historiográfica al constituir el centro de atención de un nutrido grupo de investigadores. Entre los principales estudios a ella dedicados șe encuentran Yolanda GUERRERO NAVARRETE y José María SÁNCHEZ BENITO, Cuenca en la Baja Edad Media: Un sistema de poder, Diputación de Cuenca, Cuenca, 1994; María Concepción QUINTANILla RASO, Marcos y formas de proyección de la nobleza conquense en su entorno urbano y territorial, en Congreso Internacional de Historia, El Tratado de Tordesillas y su época, 3 vols., Junta de Castilla y León, Madrid, 1995, I, p. 131-154 y Política ciudadana y jerarquización del poder. Bandos y parcialidades en Cuenca, «En la España Medieval», 20 (1997), p. 219-250; J.M. SÁNCHEZ BENITO, Territorio y conflicto en el ámbito jurisdiccional de Cuenca (época de los Reyes Católicos), «Espacio, Tiempo y Forma. Historia Medieval», 9 (1996), p. 89-118; y José Antonio JARA FUENTE, Concejo, poder y élites. La clase dominante de Cuenca en el siglo XV, CSIC, Madrid, 2000 y. The Importance of Being Earnest: Urban Elites and the Distribution of Power in Castilian Towns in the Late Middle Ages, en Isabel ALFONSO ANTÓN, Hugh KENNEDY y Julio ESCALONA MONGE (eds.), Building Legitimacy. Political Discourses and Forms of Legitimation in Medieval Societies, Brill, Leiden-Boston, 2004, p. 139-175. 
con el fin de manipularlo/adaptarlo a sus propias necesidades ideológicas y materiales.

En tal sentido, en el apartado primero analizaremos el modo de funcionar de estos procesos de percepción a partir de la manipulación por parte de los actores sociales implicados de referentes y marcadores de identidad política, cuya operación no sólo define un determinado modelo de identidad política sino también un concreto tipo de (manifestación/funcionamiento de la) percepción. Tanto en este apartado como en los apartados dos y cuatro analizaremos someramente el funcionamiento de algunos de los principales modelos referenciales de identidad política, entendiendo por tales las categorías primarias de identidad política, cuyo carácter más abstracto y general permite la reducción en ellas de esas otras categorías secundarias de identidad política (a las que aquí denominamos marcadores de identidad, cuyo funcionamiento ocupa el apartado segundo), cuya construcción se elabora a partir de las primeras, afectando a agentes, espacios y contextos sociopolíticos diversos. Sería el caso, por ejemplo, del referente «nobleza» y de algunos de sus marcadores (analizados en el apartado cuarto): «noble», «pariente», «amigo». Finalmente, en los apartados tres y cuatro examinamos el modo en el que ambos elementos de la ecuación política (nobleza y ciudad-elites urbanas) acabaron por aceptar y someterse a unos referentes identitarios compartidos, comunes (incluso cuando dicha aceptación resultó ser más táctica e ideal que práctica y real por parte de algunos miembros de la nobleza). Un proceso en el que la ciudad asumió un papel rector de gran importancia, al dirigir la urbe el proceso de confluencia de estos referentes políticos, contribuyendo a una relativa «nobilización» de los mismos (al absorber gran parte de los referentes nobles) y, al tiempo, a una también relativa «urbanización» de aquéllos, al someterlos a una relectura (a un esquema de percepción) más favorable a sus intereses.

\section{IDENTIDAD: UN RESERVORIO DE VALORES COMPARTIDOS}

El 3 de Septiembre de 1476, el concejo de Cuenca se dirige a Pero Carrillo de Albornoz, señor de Torralba y Beteta, protestando: primero, porque gentes de su casa habían entrado de noche en Chillarón y Castillejo (lugares dependientes de la jurisdicción de la ciudad), robando algunas acémilas y una mula, y tomando presos a dos vecinos de Castillejo; segundo, porque aquel obligaba a algunos lugares de la jurisdicción de Cuenca a comprarle sal; y, tercero, por proteger a Juan de Anaya, quien había cometido ciertos robos en heredades del regidor Juan de Sacedón, respecto de lo cual afirmaba la ciudad que non deue y robar en poblado e despoblado a tal onbre commo es Juan de Sasedón ${ }^{6}$.

${ }^{6}$ Archivo Municipal de Cuenca (AMC), Libros de Actas (LLAA), legajo (leg.) 200, expediente (exp.) 2, ff. 8 r-9 r. 
El documento constituye una de tantas denuncias de las violencias y excesos cometidos por la nobleza local y regional (un colectivo compuesto por representantes de la baja nobleza local, y la media y alta nobleza del reino). Pero, al mismo tiempo, ayuda a comprender la forma en la que se construían estas marcas de identidad y, a la postre, la propia identidad.

Tanto los trazos negativos que dibujan la imagen de Pero Carrillo como la sintética pero extraordinariamente rica expresión tal onbre commo es Juan de Sasedón, conducen a plantearnos el funcionamiento de la noción «identidad» alrededor de tres elementos básicos: primero, los marcadores de identidad; segundo, los procesos operativos de estos engranajes, es decir el modo en el que estos mecanismos o marcadores se ajustan para ejecutar sus funciones; $y$, tercero, el modo en que los distintos actores sociales comprenden los marcadores y sus procesos relacionales, que es decir el modo en que se verifican los diferentes procesos de percepción.

Una percepción que, al igual que los restantes elementos que configuran la identidad, adquiere un marcado carácter dialéctico y, por lo mismo, contradictorio, en ese contexto de relaciones biunívocas «yo-otros» ${ }^{7}$.

Es lo que se desprende de la carta dirigida el 15 de Marzo de 1465 a Cuenca por el corregidor Pedro de Salcedo. En ella, éste reclama al concejo que se le abone su salario de corregidor, so pena de multar a la ciudad con 30.000 o $40.000 \mathrm{mrs}$., añadiendo que no merece el trato que se le dispensa, toda vez que ha trabajado por el bien de la ciudad

[...] syn ayuda del señor obispo e de vosotros [...] por que la dicha çibdad e los vesinos de ella estouiesen fauoresçidos [...] vosotros sennores ovo conocimiento de los seruiçios e honrras e trabajos e peligros que yo por vosotros pasé, e avn quedo en asas, que tomé por enemigos, por respecto de vosotros, quantos ommes e nobles ay en esa comarca e avn los más de este reyno, los quales me solían faser muy grandes honrras e acatamientos e fallaua sus puertas abiertas quando las quería; lo qual todo yo perdy por vosotros, e la postre [non] aveysme dado el gualardón, desto non me marauillo $[\ldots]^{8}$.

Evidentemente, Pedro de Salcedo manipulaba la realidad en su propio beneficio, aunque no en tan gran medida como a primera vista pudiera pensarse. 1465 fue, sin lugar a dudas, el annus horribilis de Enrique IV quien hubo de enfrentarse a las actitudes levantiscas de un sector de la nobleza que, finalmente, le depondría en efigie en la llamada «Farsa de Ávila», el 5 de Junio de 1465, estallando uno más de los episodios de guerra civil que

${ }^{7}$ Carácter dialéctico y biunívoco que enfatizan numerosos autores, entre los que cabe mencionar los trabajos editados por P. TAP (dir.), Identités collectives et changements sociaux, op. cit. (especialmente los estudios de Marc-Henry Soulet y Marie-Claude Groshens); Sebastian Philip GARMAN, Foundation myths and political identity: Ancient Rome and Anglo-Saxon England compared, Tesis Doctoral defendida en la London School of Economics, Universidad de Londres (microforma), 1992; Iver B. NEUMANN, Collective Identity Formation: Self and Other in International Relations, «European Journal of International Relations», 2 (1996), p. 139-174; y Laurier TURGEON, Jocellyn LÉTOURNEAU y Khadiyatoulah FALL (dirs.), Les espaces de l'identité, Presses de l'Université Laval, 1997, p. IX.

${ }^{8}$ AMC, LLAA, leg. 197, exp. 3, ff. 11 v-12 r. 
jalonaron los reinados de Juan II y su hijo Enrique IV, y que se prolongarían hasta la consolidación en el trono de Isabel I.

En ese contexto, Pedro de Salcedo, como corregidor de Cuenca y su tierra (es decir, como máximo representante regio en el área), tuvo que enfrentarse a los actos de violencia cometidos por la nobleza local y regional en territorio de la jurisdicción de la ciudad; unos actos que, generalmente y en tiempos de paz, se circunscribían a la ocupación ilegal de términos en la tierra de Cuenca, usualmente protagonizados por vecinos de señorío (que, obviamente, contaban con el apoyo de sus señores); pero que también podían adoptar otros ropajes: robos, entradas y, en el escenario más siniestro para la ciudad, la ocupación militar de amplios distritos de su jurisdicción ${ }^{9}$.

Así, la misión de Pedro de Salcedo no era sencilla y el discurso que elabora para justificar la reclamación de su salario, se ajusta perfectamente a los objetivos perseguidos.

En una sociedad como la medieval, volcada en la imagen, en lo visual, la percepción se presenta como uno de los instrumentos principales de conocimiento y, por ello, Pedro de Salcedo manipula el proceso de percepción en su propio beneficio. Mediante ese discurso, el corregidor pretende insertar su conducta en un marco preestablecido de percepciones, encaminado a producir los marcadores básicos de un determinado modelo de identidad.

Efectivamente, los marcadores socio-políticos «favorecer», «servir», «honrar», «trabajar» que utiliza el corregidor para describir su conducta en relación a la ciudad, son algunos de los rasgos que conforman el modelo de identidad política propuesto por los vecinos de la ciudad de Cuenca, y especialmente su grupo dirigente ${ }^{10}$. Un modelo que forma parte de un discurso más amplio, que afecta al conjunto del reino, y al que no son ajenos otros grupos, como la misma nobleza. Así, cuando el 28 de Octubre de 1417 Diego Hurtado de Mendoza, señor de Cañete, escribe a Cuenca en respuesta a las

\footnotetext{
${ }^{9}$ Sobre estos procesos en el ámbito conquense, véanse los trabajos de M.C. QUINTANILLA RASO, Marcos y formas de proyección, op. cit. : La implantación de la nobleza y relaciones de poder en la tierra de Cuenca en la Baja Edad Media, en Joaquín Saúl GARCÍA MARCHANTE y Angel Luis LóPEZ VILLAVERDE (coors.), Relaciones de poder en Castilla: el ejemplo de Cuenca, Universidad de Castilla-La Mancha, Cuenca, 1997, p. 103-132; Política ciudadana, op. cit.; Estructuras y relaciones de poder en la tierra de Cuenca a fines de la Edad Media, en Actas de las III Jornadas Hispano-Portuguesas de Historia Medieval, La Península Ibérica en la Era de los Descubrimientos (1391-1492), 2 vols., Sevilla, 1997, I, pp. 707-736. J.M. SÁNCHEZ BENITO, Territorio y conflicto, op. cit. J.A. JARA FUENTE Que memoria de onbre non es en contrario. Usurpación de tierras y manipulación del pasado en la Castilla urbana del siglo XV, "Studia Historica. Historia Medieval», 20-21 (2002-2003), p. 73-104; Facing the depredations and fighting the predators. Urban Castile and the defence of municipal jurisdiction in the Late Middle Ages, «Imago Temporis, Medium Aevum», 1 (2007), p. 143-170; y Ciudad, poder y territorio: la pugna por el control de los alfoces urbanos y la definición del señorío concejil en la Baja Edad Media, en Actas de las I Jornadas de Investigación Histórica, Pasado, presente y futuro de las comunidades de villa y tierra, Cuéllar, 23 a 25 de Julio de 2008 (en prensa). Y José Ignacio ORTEGA CERVIGÓN, Usurpaciones de términos y abusos señoriales en la jurisdicción urbana de Cuenca a finales de la Edad Media, en Beatriz Arízaga Bolumburu y Jesús A. Solórzano Telechea (eds.), La ciudad medieval y su influencia territorial, Instituto de Estudios Riojanos, Logroño, 2007, pp. 221-238.

${ }^{10} \mathrm{He}$ analizado el uso de algunos de estos marcadores en Vecindad y parentesco. El lenguaje de las relaciones políticas en la Castilla urbana del siglo XV, en Foronda, Francois y Ana Isabe Carrasco Manchado (dirs.), El contrato político en la Corona de Castilla. Cultura y sociedad políticas entre los siglos X al XVI, Dykinson, Madrid, 2008, p. 211-239.
} 
quejas expresadas por la ciudad sobre los daños causados por su conflicto con Lope Vázquez de Acuña, señor de Buendía (ambos contendían, en la práctica, por el dominio sobre la urbe), Diego Hurtado articula su discurso alrededor de un doble eje fundamental: su independencia, es decir su no sujeción a otros (a la ciudad); y, de un modo aparentemente contradictorio, su disposición a conformarse a ese modelo de relaciones identitarias que es esencial pero no exclusivamente urbano:

que mi entençión sienpre fue e avn es de bien beuir e llanamente vsar sin debate e contienda alguna al seruiçio de Dios e de mi sennor el rey e honrra e procomún de la çibdat ${ }^{11}$.

El servicio a Dios, al rey y a la ciudad constituyen el referente último de una identidad política cuyos marcadores de identidad desglosan cada uno de dichos referentes generales ${ }^{12}$. Diego Hurtado de Mendoza acertó en su expresión sintética; Pedro de Salcedo se acercó a dichos referentes mediante un discurso más centrado en algunos de los elementos que integran dichos referentes y marcadores, pero su objetivo era el mismo: incorporar su conducta a un marco de marcadores de identidad y de percepción de dichos marcadores que pudiera ser visualizado (esto es comprendido) positivamente por la ciudad. Y es en este último ámbito en el que encuentra toda su justificación ese choque de percepciones que manifiesta el documento: primero, Pedro de Salcedo afirma la deseable pero hipotética percepción de su conducta en función de los referentes urbanos a los que pretende acomodarse; segundo, Pedro de Salcedo compara la anterior con la percepción que su conducta ha merecido real y efectivamente entre los integrantes de su propia «clase», los miembros de la mediana y alta nobleza del reino contra quienes ha tenido que actuar y que, por su defensa de Cuenca, casi cabría decir que «le han abandonado a su suerte». Aquí, la expresión de dos percepciones contradictorias acerca de su conducta se construye como un instrumento más de acomodación de la propia conducta a los parámetros definidos por la ciudad. Así, la oposición de ambas percepciones (una hipotética y otra real) se resuelve contradictoriamente en un doble sentido: por una parte, transforma la hipotética percepción de su conducta en certidumbre; por otra, incardina definitivamente esta última en el marco referencial identitario en el que se mira la urbe.

\footnotetext{
${ }^{11}$ AMC, LLAA, leg. 185, exp. 2, ff. 5 r-7 r.

${ }^{12}$ Sobre este tipo de marcadores de identidad, véase mi trabajo «Commo cunple a seruicio de su rey e sennor natural e al, procomún de la su tierra e de los vesinos e moradores de ella. La noción de 'servicio público' como seña de identidad política comunitaria en la Castilla urbana del siglo $X V$, «e-Spania» [revista electrónica,URL:http://e-spania.revues.org/document1223.html], 4 (2007), p. 1-30.
} 


\section{LA CONSTRUCCIÓN DE MARCADORES DE IDENTIDAD}

En cualquier caso, como manifiestan tanto Pedro de Salcedo como Diego Hurtado de Mendoza, el, llamémoslo así, «proceso identitario» comporta no sólo la construcción y efectiva operación de unos concretos marcadores de identidad, sino la aceptación de dichos modelos, al menos en el plano teórico. Y, efectivamente, las denuncias hechas por Pedro de Salcedo y Diego Hurtado nos hablan de su aceptación a acomodar su conducta a esos modelos de «comportamiento político».

El 8 de Diciembre de 1417, en el contexto de su enfrentamiento con Lope Vázquez de Acuña y ante las protestas de la ciudad, Diego Hurtado reiteraría lo que ya había manifestado en su carta de 28 de Octubre:

[...] bien sabedes commo yo sienpre fui justificado en mi bevir bien, e todos los míos, e agora non entiendo mudar otra costunbre sinon seguir el serviçio del Rey, mi sennor, e el pro común de esta Çibdat, aunque pese a esos buenos de profetas ${ }^{13}$;

es decir, su acomodación a unos referentes de conducta que constituían la base y fundamento del modelo de identidad política defendido por la ciudad.

Como ya hemos señalado, resulta interesante destacar cómo al tiempo que defiende su independencia/autonomía (lo hace en su escrito de 28 de Octubre y lo reproduce en el de 8 de Diciembre), Diego Hurtado reconoce e incluso declara con orgullo su sujeción a estos referentes. Y no es el único, ya que prácticamente todos los nobles que se relacionan con la ciudad encuentran el modo de vincular su conducta a los parámetros defendidos por la urbe, incluso cuando ello resultaba manifiestamente falso, y sobre todo cuando ello resultaba manifiestamente falso ${ }^{14}$.

¿Cómo podía ser ello así? Lo cierto es que en la base de ese modelo referencial de identidad existía una larga tradición de marcadores conductuales que todos los actores sociales podían aceptar sin mayores problemas y a los que podían acomodar sus conductas particulares sin incurrir, por ello, en graves contradicciones. La justificación de su conducta, tal y como la expresa Diego Hurtado (sienpre fui justificado en mi bevir bien), adquiere una dimensión religiosa y política general y, en consecuencia, se examina a la luz del cumplimiento de las prescripciones morales y éticas a las que se halla sujeto el individuo. De ahí que el discurso que fundamenta dicha justificación se articule alrededor de la noción de servicio: servicio a Dios y servicio al rey, es decir, cumplimiento de las obligaciones morales (que recaen sobre todo cristiano) y éticas (que alcanzan a todos los súbditos y naturales de la corona castellana); pero también servicio a la ciudad, en la medida en que

\footnotetext{
${ }^{13}$ AMC, LLAA, leg. 185, exp. 1, ff. 3 r-v.

${ }^{14} \mathrm{Para}$ un análisis de este tipo de procesos remito a mi trabajo Consciencia, alteridad, percepción y marcación: la construcción de la identidad de los sujetos en la Castilla urbana del siglo XV en J.A. JARA FUENTE, I. ALFONSO ANTON y G. MARTIN (coors.), Construir la identidad en la Edad Media, op. cit.
} 
dichas conductas asumen una «dimensión urbana» mediante la vinculación del actor social a ese espacio político singular.

\section{CONTRADICCIONES DISCURSIVAS}

Sin embargo, la acomodación de la conducta del actor a ese modelo referencial no se produce sin contradicciones, fundamentalmente porque en muchas ocasiones la sumisión al modelo no es sino retórica, ocultando o pretendiendo ocultar una conducta diametralmente opuesta a la que se justifica.

Es importante destacar que la llamada «sumisión retórica», aunque falsa en sus principios, implica un reconocimiento expreso del modelo referencial que asume (o incluso reprocha, llegado el caso). Reconocimiento que actúa a modo de un estadio superior del modelo de percepción, en el que una percepción positiva de la conducta no sólo sanciona esta última sino el modelo referencial de identidad al que aquélla pretende sujetarse. Así, el modelo referencial de identidad opera como referente de evaluación de las conductas pero, al mismo tiempo, su legitimidad y operatividad dependen de que la generalidad de las conductas se someta a él. Es por ello que ante una percepción negativa, el sujeto colectivo urbano manifiesta inmediatamente su posición ante esa «desviación de la norma» que, como tal, puede poner en peligro el entero sistema de identidad.

En el marco de ese reproche, la ciudad articula un discurso inteligente que incorpora, sin mayores problemas, los principales referentes políticoidentitarios que comparten ciudades y nobles. Con ello se alcanza un doble objetivo. De un lado, al «apropiarse»/servirse de unos determinados marcadores, la ciudad les proporciona una lectura urbana no discutida; es decir, en cierta medida, legitima su apropiación y manipulación ideológica por la comunidad urbana. De otro, al juzgar la conducta de la nobleza de acuerdo a unas normas de percepción y marcadores y referentes político-identitarios al menos nobles en origen, la ciudad deslegitima la oposición al uso de esas normas, marcadores y referentes; el sujeto del reproche podrá disputar sobre el contenido de la conducta que se reprocha pero no sobre el modelo ideológico-referencial que fundamenta ese juicio, facilitando, una vez más, el objetivo «urbanizador» perseguido por la ciudad.

Esto es lo que sucede una y otra vez a lo largo de un siglo en el que las revueltas nobles facilitan a la ciudad el ejercicio del reproche. Y así sucede también tras la pacificación del reino, cuando estos referentes siguen sirviendo de paraguas a los intereses de la ciudad. Como ocurre el 1 de Abril de 1482, cuando Cuenca se dirige a la Real Audiencia y Chancillería, actuando a favor de un vecino de la ciudad, Alonso Lázaro, contra quien pleitea un tal Juan Sánchez Abrojo por un robo cometido 17 o 18 años atrás ${ }^{15}$.

\footnotetext{
${ }^{15}$ AMC, LLAA, leg. 203, exp. 2, ff. $180 \mathrm{v}-181 \mathrm{v}$.
} 
Todo juicio se basa en la construcción contradictoria de una cadena de hechos que, cuando probados, permita aplicar una u otra norma. Contradictoria porque los hechos nunca son reconstruidos de igual modo por ambas partes; en la persecución de la norma jurídica que les resulte más favorable, cada parte pretende producir e imponer una determinada percepción de la realidad que les separa. En el caso que nos ocupa, Juan Sánchez Abrojo había construido/reconstruido su realidad afirmando que un vecino de Cuenca le había robado determinados bienes algunos años atrás.

Cuenca, que actúa en beneficio de su vecino, construye otro marco de percepción de aquella realidad, más favorable a Alonso Lázaro. Su argumentación, muy creativa, pretende transformar lo que no es sino una disputa privada en un problema público que, aun sin expresarlo abiertamente, hará girar alrededor de sus grandes referentes ideológico-identitarios y específicamente alrededor de su superior síntesis, el «vivir justificadamente».

Primero, contextualiza temporalmente los hechos, retrotrayéndolos a unos 17 o 18 años atrás. Esto no es baladí pues permite a Cuenca situar los hechos en los convulsos años 1465/1466, en pleno levantamiento noble contra Enrique IV, cuando algunos caballeros y prelados del reino siguieron más su querer quel serviçio del rey don Enrique, nuestro sennor.

Segundo, esto permite a la ciudad recordarle a la Audiencia que Enrique IV y luego los actuales monarcas, Isabel I y Fernando V de Castilla, ordenaron a sus súbditos hacer la guerra a los rebeldes, y que este mandato fue obedecido por la ciudad.

Tercero, Cuenca contextualiza la persona del demandante, Juan Sánchez Abrojo, quien es vecino de Tordelaguna, villa del arzobispo de Toledo, don Alonso Carrillo. La ciudad no tiene que decir más. En 1465, uno de los principales impulsores de la «Farsa de Ávila» fue, precisamente, el arzobispo de Toledo, cabeza visible de los nobles rebeldes contra Enrique IV y luego contra Isabel I.

De este modo, la ciudad produce una determinada percepción, en la que el robo se justifica/explica por las acciones militares emprendidas por la ciudad, siguiendo órdenes del rey, contra los rebeldes, en cuyas filas habría militado Juan Sánchez Abrojo. La noción «servicio» y su imagen especular, el «deservicio», permitían a Cuenca justificar una conducta aparentemente injustificable, al transformar la ilegalidad (el robo) en legitimidad (represalia).

Y si Diego Hurtado de Mendoza, y por extensión la nobleza, podían reconducir, y legitimar, su conducta a través de ese ideal sienpre fui justificado en mi bevir bien, e todos los míos; la ciudad, haciendo suya la idea que le subyace, predicará algo similar de Alonso Lázaro, que es hombre con reputación de trabajar e bevir por su puro afán e trabajo, commo ome temiente a Dios; es decir, el perfecto ciudadano y súbdito.

De esta manera, un juicio sobre la conducta privada de un vecino de Cuenca, se transforma en un juicio sobre la conducta pública de un sector de la nobleza, y de la propia ciudad, y su acomodación a unos referentes políticoidentitarios que nadie discute. 
Ahora bien, merece la pena señalar que, en su relación con la nobleza, el discurso urbano incorpora aquellos referentes a un marco ideológico propiamente noble; como se ha señalado con anterioridad, por este procedimiento la ciudad se asegura la construcción de un modelo de percepción en el que lo único discutible es el ámbito de los hechos, respecto de los cuales también se asegura la construcción de una cadena narrativa que confiera una razonable apariencia de realidad a su discurso. La nobleza queda, así, entrampada en su propio juego.

Cuando, a fines de la década de los sesenta, surge la ocasión de designar nuevo obispo de Cuenca, los candidatos no faltan precisamente entre las más importantes casas nobles del reino. Y la ciudad, que observa con horror las posibles consecuencias de una tal nominación, establece sus propias alianzas y promueve a su propio candidato. Desde su designación como guardas mayores de Cuenca y su tierra, en $1419^{16}$, los Hurtado de Mendoza han ido paulatinamente construyendo una amplia red de relaciones en el interior de la urbe, definitivamente consolidada en la década de los 60, merced al apoyo que los señores de Cañete acordaron prestar a la monarquía en sus conflictos con la nobleza rebelde. Esto también supuso una suerte de apoyo a la aspiración de la ciudad de mantenerse dentro del dominio regio y no ser entregada a ningún noble. Por ello, en 1469 se unen los intereses de los Hurtado de Mendoza, que aspiran, como otros nobles, a dicho solio episcopal, y de Cuenca, que pretende evitar que se instale en la ciudad alguno de los principales linajes nobles del reino y, por esta vía, la ciudad acabe entregada a la nobleza. Y así, el 31 de Mayo de 1469, el concejo de Cuenca escribía al rey, pidiéndole que apoyara al candidato de la ciudad, Juan Hurtado de Mendoza, por su

[...] benina e noble condición [...] e quan contentos seriamos todos con el, asy los eclesiásticos commo los seglares [...] [y su] muy grand afeçión a vuestro seruiçio e al bien e honra desta vuestra çibdad ${ }^{17}$.

En este documento, el concejo somete a Juan Hurtado a una cadena de evaluaciones que principia con referentes propiamente nobles y finaliza con referentes claramente urbanizados. En este sentido, si el servicio al rey se presenta como ese gran territorio común que todos comparten; el servicio a la ciudad supone la «urbanización» de una relación servicial que, propiamente, somete a la nobleza ( $\mathrm{y}$, en general, a los súbditos del reino) a su rey. Evidentemente, no es la primera vez que la ciudad se sirve de este modelo referencial político-identitario; lo que importa destacar es que su uso se halla tan asimilado por los diferentes cuerpos de la estructura social castellana, al menos en el plano ideológico, que se puede utilizar sin problemas para sustentar una petición de tal gravedad.

\footnotetext{
${ }^{16}$ AMC, LLAA, leg. 185, exp. 4, ff. 9 r-v.

${ }^{17}$ AMC, LLAA, leg. 198, exp. 3, f. 53 r.
} 
Ahora bien, tan importante como ello es el uso que se hace de los referentes específicamente nobles y concretamente de la condición del actor social, de su condición noble. La percepción y reconocimiento de dicha condición es uno de los grandes campos de batalla para la nobleza, pues se sirve de ella como paraguas ideológico, como contrafactual que oponer a la realidad, menos amable, de muchos de sus actos.

El 21 de Octubre de 1417, temiendo que Diego Hurtado de Mendoza aproveche una visita a la ciudad para ocuparla con sus gentes, Cuenca le envía mensajeros rogándole o exigiéndole, en realidad, entrar en la ciudad con un cortejo reducido $^{18}$. La respuesta dada por Diego Hurtado, el 28 de Octubre, rechazaba toda injerencia de la ciudad en la expresión de aquello a lo que su condición le obligaba, afirmando que

\begin{abstract}
[...] es mi entençión de entrar en estado que cunpla a mi honrra, conuiene a saber, con mis escuderos que biuen conmigo e lieuan de mí sueldo e tierras e acostamiento e comen continuamente pan a mis manteles, e non con gente allegadisa nin enprestada nin con tal gente que por ello se pueda leuantar alboroço en la çibdat ${ }^{19}$;
\end{abstract}

pues, como él mismo indica, lo contrario sería actuar en deservicio de Dios, del rey y de la ciudad. Aunque finalmente, no llegó a acudir a Cuenca, en Diciembre reiteraría dicha actitud, y lo mismo haría en Agosto del año siguiente cuando su concepto de un séquito apropiado, que no deshonrara su condición, implicó rodearse de una milicia de a pie y a caballo, lanceros y ballesteros, y efectuar una pequeña demostración armada ante la ciudad, haciendo desfilar sus tropas a través del puente de El Canto y de los arrabales de Barrionuevo, Carretería y Campo de San Francisco, bajo las mismas murallas de la ciudad ${ }^{20}$.

En el fondo de dicho choque de percepciones late la visión de una violencia señorial que la ciudad califica de ilegítima y la nobleza justifica mediante la defensa de su condición y el ejercicio de sus derechos señoriales. Así, el 12 de Abril de 1468 don Rodrigo Manrique, conde de Paredes de Nava, escribe a Cuenca quejándose de que sus vasallos son prendados cuando acuden a tierra de Cuenca a comprar sus mantenimientos y exigiendo que cese dicha situación, so pena de verse obligado a hacer justicia a sus vasallos:

[...] en lo qual, demás de faser lo que deuéys en ello, yo vos lo gradeçeré e terné en quenta para faser por vosotros e por todos los desa çibdad lo que cunpla. En otra mannera, sería quexoso e non me podría escusar de remediar los míos por mannera que su derecho non perdiesen, e sy dello algund enojo se siguiere a esa çibdad, sería a vuestro cargo e non al mío, a lo qual vos ruego que non deys lugar ${ }^{21}$.

\footnotetext{
${ }^{18}$ AMC, LLAA, leg. 185, exp. 1, f. 29 v.

${ }^{19}$ AMC, LLAA, leg. 185, exp. 2, ff. 5 r-7 r.

${ }^{20}$ AMC, LLAA, leg. 185, exp. 2, ff. 25 r-26 v; y leg. 185, exp. 3, ff. $15 \mathrm{v}-16 \mathrm{v}$.

${ }^{21}$ AMC, LLAA, leg. 198, exp. 2, f. 21 r.
} 
La reacción de la ciudad no es muy distinta cuando se trata de defender sus intereses. Cuando en Enero de 1442, Gómez Carrillo prendía a Juan González de Alcalá, regidor y procurador a Cortes, cuando se dirigía a la reunión de Cortes, los referentes utilizados para denunciar el exceso del noble son los mismos: actuar mediante el uso de una fuerza que es ilegítima porque contradice el servicio del rey y de la ciudad; frente a lo cual, anuncian la oposición de una fuerza legítima para liberar al regidor,

[...] por todas las vias, otrosy de derecho commo fecho, segunt entendieremos que es complidero a serviçio del dicho sennor rrey e a rreparo de la dicha injuria [...] e mas, de nos quexar e querellar de vos al dicho sennor rrey [...] e si por causa e rason de los sobre dicho, algunos escandalos se recreçieren, e muertes e feridas, e robos e males e dannos se recreçieren, que vos, el dicho Gomes Carrillo, con vuestros bienes, seades a todo ello tenido e obligado ${ }^{22}$.

\section{PositiVAndo LAS RELACIONES SOCIALES}

Es habitual que el concejo responda, o se reserve el derecho a responder, con violencia a las violencias ilegítimas ejercidas por la nobleza; como hemos visto que sucedía en el documento anterior o sucede en otro de Marzo o Abril de 1465, en el que anticipa, punto por punto, la argumentación que, en circunstancias similares, utilizaría don Rodrigo Manrique en 1468. En 1465 , ante unas prendas ilegítimas hechas en vecinos de Cuenca por un vasallo de Pedro de Peralta, señor de la Puebla de Almenara, la ciudad solicita a éste que se haga justicia a sus vecinos pues, de lo contrario nos será forçado de proueer a nuestros vesinos con justiçia e non dar lugar que asy sean robados e maltratados ${ }^{23}$.

La similitud de las argumentaciones de Cuenca y don Rodrigo Manrique reconducen una vez más nuestra encuesta hacia un marco referencial (ideológico e identitario) estrechamente compartido por ambos cuerpos socio-políticos.

Pero no es sólo en este recurso a la violencia donde se verifica este tipo de coincidencias. La ciudad se sirve de la condición noble para aventar el miedo a la vergüenza, al deshonor al que podría llevar al noble de turno su conducta; como sucede el 2 de Junio de 1483, cuando amenaza a Diego de Saelices con denunciar su conducta a los reyes si no libera a un vecino de Cuenca que tiene preso en la villa de Beteta, enfatizando que dello se vos podría seguir daño e asas vergüença ${ }^{24}$.

No obstante, en este juego la ciudad no está sola. La nobleza también manipula estas nociones para granjearse la buena voluntad del concejo. Ya hemos visto cómo el 28 de Octubre de 1417, Diego Hurtado declaraba

\footnotetext{
${ }^{22}$ AMC, LLAA, leg. 190, exp. 6, ff. $20 \mathrm{v}-21 \mathrm{r}$.

${ }^{23}$ AMC, LLAA, leg. 197, exp. 3, ff. 29 v-30 r.

${ }^{24}$ AMC, LLAA, leg. 205, exp. 2, ff. 25 v-26 r.
} 
hallarse al seruiçio de Dios e de mi sennor el rey e honrra e procomún de la çibdat. El 31 de Marzo de 1467, Lope de Alarcón, señor de Valverde, escribía a Cuenca, dirigiéndose a sus sennores parientes e amygos. Conçejo, regidores, oficiales e ommes buenos dela muy noble çibdad de Cuenca, lamentando el apresamiento de un vecino de la ciudad y declarando que tan pronto conocieron sus vasallos dicha condición (la vecindad conquense), dejaronlo e fisieronle onrras ${ }^{25}$. Así pues, el honor, tanto del noble como de la ciudad, constituía un permanente elemento de diálogo entre ambas partes. Nótese, además, cómo en el último documento citado, ese honor es vinculado a una condición superior en el caso de la ciudad, su nobleza. No es la primera vez que la urbe articula su discurso alrededor de dicho marcador social, buscando forzar una determinada percepción; lo que interesa destacar es el éxito alcanzado en dicha empresa, pues tampoco sería Lope de Alarcón el primer noble en acomodarse a ese modelo de percepción del estatus de la urbe. Éxito que alcanza todo su significado si tenemos en cuenta que el rey no concedería a Cuenca el título de noble hasta Noviembre del año siguiente, $1468^{26}$

El uso de dicho marcador socio-identitario, «noble», ilustra perfectamente la comunión de referentes que se produce entre nobleza y ciudad; y no fue el único caso. Pocos meses después de resolverse el contencioso con Lope de Alarcón, el 20 de Mayo de 1467, don Rodrigo Manrique se quejaba a Cuenca de las prendas que la ciudad hacía en sus vasallos. El conde de Paredes, haciendo gala de gran tacto, dirigía su misiva a los honrados conçejos, justicia, regidores, caualleros, escuderos, ofiçiales e ommes buenos dela muy noble çibdad de Cuenca, parientes e espeçiales amigos ${ }^{27}$; mediante dicha intitulación, el noble señor reconocía, una vez más, la condición noble de la ciudad, añadiendo un elemento adicional de vinculación al universo noble, la formulación de una relación de parentesco ficticia (sus parientes), así como la incorporación de la ciudad al colectivo de íntimos del condestable (e espeçiales amigos). Álvaro de Luna, condestable de Castilla y conde de San Esteban, ya había ensayado ese tipo de formulación el 27 de Febrero de 1436, cuando escribía a sus amigos, las autoridades y vecinos de Cuenca, solicitando que nombraran procurador a Cortes a su primo Gómez Carrillo ${ }^{28}$. Y don Juan Pacheco, marqués de Villena, al pactar una suerte de paz de alcance regional, en pleno conflicto civil, entre él y el concejo de Cuenca, recupera estos referentes, ampliando su marco efectivo de actuación mediante la introducción de un conjunto más completo de referentes socio-políticos. Así, el 13 de Marzo de 1467, don Juan se dirige a las villas de su marquesado declarando que

\footnotetext{
${ }^{25}$ AMC, LLAA, leg. 198, exp. 1, ff. 24 v-25 r.

${ }^{26}$ AMC, LLAA, leg. 198, exp. 2, ff. 60 r-v.

${ }^{27}$ AMC, LLAA, leg. 198, exp. 1, f. 46 v.

${ }^{28}$ AMC, LLAA, leg. 189, exp. 1, ff. 5 v-6 r.
} 
Yo, don Juan Pacheco, marqués de Villena, mayordomo mayor del rey nuestro sennor e del su Consejo, fago saber a vos, los conçejos, justiçias, regidores, caualleros, escuderos, ofiçiales e ommes buenos de la mi çibdad de Chinchilla e de las villas e lugares del mi marquesado de Villena e del Infantadgo, que mi entençión e voluntad es que vosotros tengades buena amistad, pas, amor e concordia de aquí adelante con el conçejo, justiçia, regidores, caualleros, escuderos, ofiçiales e ommes buenos y moradores dela çibdad de Cuenca e de todos los lugares de su tierra, por quanto la dicha çibdad e tierra de Cuenca ha prometido e jurado de vos guardar la dicha amistad, pas, amor e concordia $[\ldots]^{29}$.

Efectivamente, Cuenca se había comprometido a ello el 16 de Febrero, entendiendo que ello era

conplidero a seruiçio del rey don Enrique, nuestro sennor, e al bien e interese público desta dicha çibdad de Cuenca e su tierra e de los vesinos e moradores della ${ }^{30}$.

Cuenca no desaprovecharía la ocasión de asimilar dicho proceder y así la vemos dirigirse a algunos de sus principales vecinos usando el doble apelativo de pariente e amigo (en el caso de Pero Suárez de Toledo, el 3 de Septiembre de 1476), o el más gráfico de hermano (en el caso del regidor Rodrigo de Torres, el 24 de Junio de 1482) ${ }^{31}$. En ambos casos, el concejo, la máxima representación de la clase dominante de Cuenca, se dirigía a integrantes de los más importantes linajes de la ciudad, miembros del regimiento y pertenecientes al círculo interior de la clase dominante. La exclusividad propia de lo noble no se disolvía enteramente en lo urbano, preservando de este modo su «lógica de clase» ${ }^{32}$.

Esta relación, basada en relaciones de parentesco y amistad, encuentra un fuerte fundamento en la proximidad, en el contacto cotidiano, en la vecindad, como muy bien expresa Álvaro de Mendoza, señor de Requena, el 22 de Noviembre de 1465 cuando, tras dirigir su carta a los honrados sennores, parientes de la ciudad Cuenca, pide la restitución de unas prendas hechas a unos vasallos suyos y declara su deseo de que

pues avemos de ser vecinos, hagamonos tales obras que sean mas de parientes y de amigos que de al, por que delo contrario yria fuera de mi condiçion $^{33}$.

${ }^{29} \mathrm{AMC}$, LLAA, leg. 198 , exp. 1 , ff. $19 \mathrm{v}-20 \mathrm{r}$.

El 15 'de agosto de 1479 , su hijo, Diego López Pacheco, duque de Escalona y marqués de Villena, otorgaría a Cuenca una carta de tregua y seguro en todo similar a la anteriormente citada. Cfr. AMC, LLAA, leg. 201, exp. 1, ff. 73 v-74 v bis.

${ }^{30} \mathrm{AMC}$, LLAA, leg. 198, exp. 1, ff. $19 \mathrm{v}-20 \mathrm{r}$.

${ }^{31}$ AMC, LLAA, leg. 200, exp. 2, ff. 8 r-9 r; y leg. 203, exp. 2, f. 255 r.

${ }^{32}$ De la manipulación de estos referentes por parte de la ciudad (y la nobleza), me he ocupado en Vecindad y parentesco, op. cit.

${ }^{33}$ AMC, LLAA, leg. 197, exp. 1, f. 19 v. 
Casi 40 años antes, el 20 de Julio de 1423, Diego Hurtado de Mendoza había vinculado esa especial relación no ya a la simple vecindad sino a la naturaleza (con amor verdadero de naturalesa que por esa dicha çibdat so entregado para faser todas las cosas que a pro e bien della e de su tierra $s e a n)^{34}$, es decir a la ciudadanía política que ostentaba el noble señor de Cañete por su condición de vecino y guarda mayor de ciudad y tierra. Lo mismo haría su hijo, Juan Hurtado de Mendoza, el 4 de Abril de $1468^{35}$.

De este modo, la ciudad incorporaba a su vocabulario y prácticas políticas unos referentes que habían encontrado su previo anclaje en el universo noble; de este modo, también, ambas agrupaciones sociales encontraban o construían un espacio de diálogo y relaciones en el que ideológicamente coincidían, facilitando el proceso de comunicación y encuentro.

Ahora bien, ¿qué alcance real tuvo ese proceso de comunicación ideológica? En general, podríamos decir que redujo el espacio de debate. Evidentemente, ni eliminó ni redujo las agresiones nobles a los intereses de la ciudad (especialmente las ocupaciones ilegales de distritos de jurisdicción urbana), pero sí reconcilió a ambas partes alrededor de unos referentes conocidos y compartidos por ambos. En la práctica, esto significa que ciudad y nobles tácitamente acordaron juzgar sus respectivas conductas a la luz de unos mismos principios, lo que facilitaba tanto el diálogo como la reducción de la conflictividad a niveles asumibles por ambas partes; sobre todo si tenemos en cuenta que, salvo en el caso de grandes invasiones armadas de sus términos (como las protagonizadas por el duque de Medinaceli en la década de los 70), la ciudad sí supo oponer su propia violencia (legítima) a la (ilegítima) violencia ejercida contra ella por la nobleza.

De este modo, cuando, en Marzo de 1469, Pero Carrillo de Albornoz, regidor de Cuenca y señor de las villas de Torralba, Beteta y Alcantud, protesta a Cuenca por el trato que la ciudad dispensa a sus vasallos

non myrando la naturalesa mas antigua que de my e vesindad e amor e debdo que yo tengo e en my se ha fallado ${ }^{36}$;

Cuenca es capaz de trasladar el ámbito del debate y del reproche de su conducta a la del noble, juzgando ambas conductas no en función de criterios o principios introducidos ex novo en el conflicto sino a partir de la propia argumentación del noble:

[...] vos respondiendo, noble sennor, sy bien mirar quisiéredes a lo que soys obligado, çiertamente quanto mayor e más antigua naturalesa tengáys enesta çibdad o vesindad, mayor cargo tenéys e vos puede ser cargado destas cosas [...] pues vos soys criado e seruidor del rey nuestro sennor, çierto non devriedes reprochar [la actuación de la ciudad] [...] non lo

\footnotetext{
${ }^{34}$ AMC, LLAA, leg. 187, exp. 2, ff. 22 r-v.

${ }^{35}$ AMC, LLAA, leg. 198, exp. 2, f. 18 v.

${ }^{36}$ AMC, LLAA, leg. 198, exp. 3, f. 24 r.
} 
deviérades aver agrauio e, mayormente, mirando vuestro deseo que mostráys al seruiçio del rey nuestro sennor, querríamos que non diésedes lugar a estas cosas, ca dellas conosçido deseruiçio viene a su altesa e avn a vos, noble sennor, grand infamia, e non conosiemos a vos venir honra nin prouecho ${ }^{37}$.

Así, la ciudad juzga la conducta del noble señor de Torralba a la luz de la declaración y principios socio-políticos expuestos por aquel: naturaleza y vecindad, amor y deudo, servicio al rey y a la ciudad. Contrariamente a lo manifestado y esperado por Pero Carrillo, el resultado del examen de su conducta es claramente negativo. Frente al vínculo de naturaleza que él esgrime, alegando los derechos que derivan de esa relación política, la ciudad enuncia las obligaciones que se derivan de aquél y a cuya luz la conducta de Pero Carrillo podría ser considerada en deservicio del rey, infame y deshonrosa.

Casi medio siglo antes, el 20 de Julio de 1423 Diego Hurtado de Mendoza se servía de un procedimiento argumentativo similar, aunque ahora oponiendo su buena voluntad a la no buena entençión de algunos de los oficiales del concejo; la piedra de toque usada por el noble para valorar las respectivas conductas se hallaba en su

amor verdadero de naturalesa que por esa dicha çibdat so entregado para faser todas las cosas que a pro e bien della e de su tierra $\operatorname{sean}^{38}$.

\section{CONCLUSIONES}

Nobleza y ciudad constituyen, a lo largo del siglo XV, dos grandes agrupaciones socio-políticas antagónicas debido, sobre todo, a las miradas predatorias que dirige la primera hacia el patrimonio e incluso la entera constitución política (pertenencia al realengo) de la segunda.

Sin embargo, gradualmente ambos universos irán acercándose en el plano ideológico, encontrando puntos de comunicación que, en el caso de la ciudad, supondrá asumir, con un alto nivel de éxito, algunos de los referentes político-identitarios que generalmente identificaban a la nobleza.

Paradójicamente, esto no supondrá un triunfo paralelo del colectivo noble. La asunción por la ciudad de parte del ideario identitario noble produjo el doble efecto de, primero, facilitar el proceso de comunicación entre ambas partes mediante la introducción de unos referentes lingüísticos (sociopolíticos) comunes; y, segundo, reducir el ámbito del debate a lo puramente factual, toda vez que ambas partes habían sabido asumir unos mismos elementos ideológico-discursivos. Por lo tanto, el ámbito del debate se centró en las conductas de las partes (no sólo pero sí especialmente con ocasión de los conflictos que las enfrentaron), así como en la adecuación de esas conductas

${ }^{37}$ AMC, LLAA, leg. 198, exp. 3, f. 24 v.

${ }^{38}$ AMC, LLAA, leg. 187, exp. 2, ff. 22 r-v. 
a los principios rectores aceptados por ambas partes; lo que ya no estaba en juego era, precisamente, lo más importante, la definición de esos principios.

Unos principios que giraron, por un lado, alrededor de un gran referente político-identitario, la noción «servicio» (a Dios, al rey, a la ciudad) $\mathrm{y}$, de otro, de todo un conjunto de marcadores de identidad (amor, vecindad, amistad, parentesco, honor...) no todos específicamente urbanos en origen. En ellos se mirarían nobles y ciudad para hallar la justificación de su conducta; y sobre ellos, y defendiéndose de las agresiones nobles, construiría la ciudad un discurso del deservicio noble. Un discurso que, a la postre, triunfaría sobre las violencias nobles con el triunfo definitivo de Isabel I en la última guerra civil que vería el siglo XV en Castilla.

De este modo, la identificación de los diversos referentes y marcadores de identidad política que se hallaban en juego en dicho contexto político y entre dichos agentes sociales, y la definición de los diferentes modelos de percepción operados en dicho tiempo y espacio (y actuados por aquellas agrupaciones sociopolíticas, nobleza y elites urbanas), facilitan el análisis de los tipos de relaciones establecidos entre dichos actores sociales, de la evolución en el tiempo de dichos marcos relacionales, y de la definición y explicación de las posiciones sociopolíticas ocupadas por cada uno de ellos en cada momento. Si referentes y marcadores de identidad constituyeron escalones diferentes de unos modelos fundamentalmente (teórico) discursivos, su análisis constituye un instrumento precioso para comprender y valorar no sólo la dimensión ideológica de dichos instrumentos y procesos sino su virtualidad material, en la medida en que constituyen un buen reflejo de la realidad y objetivos políticos de dichos sujetos, así como de su capacidad para desenvolverse en el entorno sociopolítico concreto, circunstancia especialmente reseñable en el caso de las ciudades (y sus máximos representantesvaledores, las elites urbanas), cuya capacidad de posicionamiento y actuación frente a las aspiraciones de la nobleza (sobre todo alta y mediana nobleza) no siempre han recibido la valoración positiva que merecen.

Fecha de recepción del artículo: agosto 2008.

Fecha de aceptación y versión final: diciembre 2009. 